\title{
Instability in smoking patterns among school leavers in Victoria, Australia
}

\author{
Penelope E Schofield, Ron Borland, David J Hill, Philippa E Pattison, Marienne E Hibbert
}

Centre for Behavioural Research in Cancer, Anti-Cancer Council of Victoria, Carlton

South, Victoria,

Australia

P E Schofield

$\mathrm{R}$ Borland

D J Hill

Department of Psychology, University of Melbourne, Melbourne, Victoria

P E Pattison

Centre for Adolescent Health, Royal

Children's Hospital,

Melbourne

M E Hibbert

Correspondence to: Dr PE Schofield, Centre for Behavioural Research in

Cancer, 1 Rathdowne Street, Carlton South, Victoria 3053, Australia. penny@accv.org.au

\begin{abstract}
Objective-To describe patterns of smoking in a cohort of young adults over the first 15 months after leaving school.

Design-A four-wave, longitudinal survey design was used to gather data. Final-year students from 93 schools completed the recruitment questionnaire at an average age of 17 years. Follow-up questionnaires were posted to their home addresses three months, nine months and 15 months after the end of school.
\end{abstract}

Setting-Victoria, Australia.

Participants-A cohort of 1903 respondents who completed and returned all four questionnaires.

Main outcome measures-Self-labelled smoking status ("heavy smoker", "light smoker", "occasional smoker", "exsmoker", and "non-smoker"), daily cigarette consumption, and maximum daily cigarette consumption.

Results-At school, $72 \%$ of the sample were "non-smokers", 5\% "ex-smokers", $11 \%$ "occasional", $8 \%$ "light", and 5\% "heavy smokers". At 15 months after school, these proportions had shifted to $64 \%, 8 \%, 11 \%, 9 \%$, and $7 \%$, respectively. Over the study, "light smokers" and "heavy smokers" substantially increased their daily consumption; "occasional" and "ex-smokers" did not. There was relatively high stability in self-labelled smoking status at one wave and the next. However, over the four waves, $38 \%$ of the sample changed their self-labelled smoking status, and $41 \%$ of these had been "non-smokers" at school. A reduced second-order Markov chain model was found to fit this four-wave behavioural sequence. Detailed description of smoking status changes revealed greater progression to higher levels of smoking than transition to lower levels.

Conclusions-There is considerable flux in smoking patterns among young adults after leaving school, suggesting an opportunity to intervene with smoking prevention programmes at this stage of development.

(Tobacco Control 1998;7:149-155)

Keywords: smoking patterns, young adults, Australia

Introduction

While priority in research and prevention activity for tobacco control has been given to school-age populations, considerably less attention has been given to the possibilities for prevention of regular smoking among young people in the period after leaving school. Given the many transitions and changes that occur in a young person's life at this time, including new freedoms, rights, responsibilities, and pressures, it might be expected that an individual's use of tobacco would be relatively volatile. It would therefore be amenable to change towards either greater or lesser levels of use depending upon the influences to which the individual is exposed. At this stage, little is known about young adult smoking because there are only a few multiwave, longitudinal studies. This paper describes the patterns of smoking exhibited by young adults after leaving school.

School-based interventions to prevent tobacco experimentation have had limited success in the short term and the impact of programmes tends to diminish with time. ${ }^{12}$ In Australia, around $90 \%$ of schools report providing health education classes on smoking for each year level (except the final secondary school year), ${ }^{3}$ but the prevalence of smoking is still high among school students. ${ }^{4}$

The bulk of experimentation with smoking occurs during adolescence. About threequarters of Australian students in year 12 (16-18 years) report some experience of smoking. ${ }^{4}$ Very few people in the United States first try smoking after the age of $20 .^{56}$ Researchers agree that the major risk period for initiation into tobacco use is in mid to late adolescence ${ }^{57}$; however, a small amount of uptake after leaving school has been observed. ${ }^{56}$ In a recent Australian study, $28 \%$ of male and $31 \%$ of female students in year 12 were classified as current smokers; however, only $15 \%$ of boys and $13 \%$ of girls reported smoking daily. ${ }^{4} \mathrm{~A}$ dramatic increase in regular smoking must occur after leaving school, as the prevalence of self-defined Australian smokers aged $20-24$ is about $36 \%,{ }^{8}$ of whom about $90 \%$ are likely to be daily smokers. ${ }^{9}$

In contrast to the wealth of research on smoking initiation, less has been done on the progression to regular smoking. ${ }^{10}$ It is known that smoking during adolescence leads to smoking in young adulthood, with the more years of uninterrupted smoking and higher consumption carrying the greatest risk..$^{61-17}$ The US Surgeon General's report on preventing tobacco use ${ }^{7}$ posits that if high-school students "can be kept tobacco-free, most will never start using tobacco" (page 5). Single follow-up data indicate that many adult smokers were regular smokers in their teens, but an 
Table 1 Demographic characteristics of respondents with complete data

\begin{tabular}{|c|c|c|c|c|c|c|c|c|}
\hline & \multicolumn{2}{|c|}{ Wave 1} & \multicolumn{2}{|c|}{ Wave 2} & \multicolumn{2}{|c|}{ Wave 3} & \multicolumn{2}{|c|}{ Wave 4} \\
\hline & $\%$ & $n$ & $\%$ & $n$ & $\%$ & $n$ & $\%$ & $n$ \\
\hline \multicolumn{9}{|l|}{ Sex } \\
\hline Male & 36 & $(689)$ & NA & NA & NA & NA & NA & NA \\
\hline Female & 64 & (1214) & NA & NA & NA & NA & NA & NA \\
\hline \multicolumn{9}{|l|}{ Age (years) } \\
\hline 16 & 8 & $(148)$ & NA & NA & NA & NA & NA & NA \\
\hline 17 & 79 & (1501) & 21 & (393) & 2 & (35) & NA & NA \\
\hline 18 & 13 & $(238)$ & 70 & (1335) & 68 & (1307) & 21 & (391) \\
\hline 19 & $<1$ & (16) & 9 & (163) & 27 & (515) & 70 & (1335) \\
\hline 20 & NA & & $<1$ & (12) & 2 & (46) & $<1$ & (12) \\
\hline 21 & NA & & NA & & NA & & NA & \\
\hline \multicolumn{9}{|l|}{ Occupation } \\
\hline Unemployed & NA & & 10 & $(196)$ & 7 & $(134)$ & 8 & $(144)$ \\
\hline Study only & 100 & & 44 & $(826)$ & 40 & $(756)$ & 31 & $(580)$ \\
\hline Work only & NA & & 10 & (199) & 16 & $(309)$ & 20 & $(382)$ \\
\hline Study part time and work $\dagger$ & NA & & 5 & (91) & 7 & $(132)$ & 8 & $(160)$ \\
\hline $\begin{array}{l}\text { Study full time and work } \\
\text { part time }\end{array}$ & NA & & 31 & $(584)$ & 30 & $(570)$ & 33 & $(635)$ \\
\hline \multicolumn{9}{|l|}{ Accommodation } \\
\hline Parents/guardians & Not & sked & 82 & $(1564)$ & 81 & $(1532)$ & 78 & (1473) \\
\hline Relatives/family friends & Not & sked & 4 & $(75)$ & 4 & (73) & 4 & $(68)$ \\
\hline House/flat with friend & Not & sked & 7 & $(125)$ & 7 & (127) & 9 & $(176)$ \\
\hline House/flat with partner & Not & sked & NA & $\mathrm{NA}^{\star}$ & 2 & $(34)$ & 3 & $(57)$ \\
\hline College & Not & sked & 5 & (93) & 5 & (90) & 5 & (88) \\
\hline Other & Not & sked & 2 & (39) & 2 & (41) & 2 & (36) \\
\hline
\end{tabular}

^Included in "Other".

†"Work" includes part time and full time.

$\mathrm{NA}=$ not applicable.
The results from this research indicated that few people initiated smoking after leaving school; however, there was a noticeable increase in the proportion of daily smokers. More than $70 \%$ of the sample were not daily smokers at school or at subsequent follow-up periods and $14 \%$ of the respondents were daily smokers throughout the study period.

This paper provides a detailed description of the stability and change in smoking among a cohort of young adults surveyed four times over a 21-month period, from the last months of secondary school to about 15 months after leaving school. The specific aims were twofold: first, to describe stability and change in smoking status nine, 15, and 21 months from baseline; and second to characterise the self-labelled smoker type in terms of reported weekly and maximum daily cigarette consumption for the four waves of data.

\section{Methods}

SAMPLE

The sample consisted of 1903 participants who had complete smoking status data for all four waves of data collection. Sociodemographic characteristics of the sample are presented in table 1 . There were more young women than young men, reflecting, in part, greater school retention of girls than boys in Victoria. ${ }^{29}$ Most of the sample were aged 17 at the wave 1 survey. Shortly after leaving school (wave 2), most of the respondents (44\%) were solely engaged in further study. Only $11 \%$ of the sample were working full time and $10 \%$ were unemployed. These proportions were similar for the next two waves except for small rises in the percentage working and corresponding decreases in those unemployed or only studying. Virtually all lived in the family home, at wave 1 , and $23 \%$ moved out over the study period.

Almost a quarter of respondents (24\%) came from a home where a language was spoken other than or in addition to English. A fifth of the respondents' mothers and $26 \%$ of their fathers smoked. The distribution of the highest level of education achieved by respondents' fathers is as follows: $38 \%$ did not finish secondary school, $29 \%$ completed secondary school or held a trade certificate, and 33\% held a university degree or diploma.

\section{INSTRUMENTS}

The study covered a range of health issues relevant to young adults; however, only measures of smoking relevant to this paper are described. The recruitment questionnaire was short, but those for the subsequent three waves were more detailed. We asked participants to identify a smoker type that best described them. Self-labelled smoker type was measured (at all four waves) using the stem: "At the present time, do you consider yourself ..." and response options: "heavy smoker", "light smoker", “occasional smoker", “ex-smoker", and "non-smoker". ${ }^{30}$ This measure was found to have a test/retest reliability of 0.96 over an interval of a week using a sample of 138 university students. A biochemical validation main exception is the "Monitoring the Future" survey, which follows up respondents every two years after high-school graduation. ${ }^{18} 1928$ 
study of people aged between 15 and 18 years showed that self-reported smoking status is highly accurate. ${ }^{31}$

Smokers and ex-smokers were asked about their cigarette consumption in the week before the survey. Maximum daily consumption (waves 2-4) was measured by asking: "What is the largest number of cigarettes you smoked on any one day in the last seven days?" The test/retest reliability was high for this item at 0.81 (one-week interval and the same sample). Weekly consumption was assessed (in all waves) by the question: "About how many cigarettes or packets of cigarettes, if any, have you smoked in the last week?" The response format allowed for subjects to write in total number of cigarettes or number and size of cigarette packs. This was divided by seven to get daily consumption.

DESIGN AND PROCEDURE

A simple random sample of 99 schools was drawn to represent proportionally secondary schools in the state of Victoria in Australia. Six schools refused to participate, leaving 93 consenting schools. Entire classes of students in year 12 were recruited into the study in mid1993. The four-page A4 $(21 \times 30 \mathrm{~cm})$ recruitment questionnaire requested signed informed consent from students, contact information, and baseline smoking status. Teachers distributed and collected questionnaires following a standard procedure. The questionnaire was completed under "test conditions". Envelopes for completed questionnaires were provided to ensure confidentiality.

Returned recruitment questionnaires were rejected for one of the following reasons: no contact details or clearly fictional ones; refusal of permission to follow up; totally implausible responses to key questions; did not give age or sex; or were not aged between 16 and 19 years. This left 6176 recruits from 7072 returned recruitment questionnaires.

From this pool of recruited participants, 3300 randomly drawn people formed the base sample who were posted wave 2 questionnaires in February 1994; 2589 questionnaires were returned completed. Those who returned the wave 2 questionnaire, had not refused further questionnaires, and were contactable over the survey period (that is, living in Victoria) were sent the wave 3 questionnaire in August 1994 $(\mathrm{n}=2577)$, and 2215 questionnaires were returned completed. For wave 4, in February 1995, 2369 participants met the same criteria as for wave 3, yielding 2007 completed questionnaires.

Three strategies were used to enhance response rate: intensive telephone follow up of non-respondents, mailing out second copies of questionnaires, and randomly allocated prizes for respondents.

A total of 1903 people returned all four of their questionnaires with smoking status data complete. This gives an effective return rate of $58 \%$. Over the course of the study, 234 respondents were lost - that is, had moved out of frame (the state of Victoria), were deceased, or the questionnaire was returned to sender-which gives a response rate of $62 \%$ over the last three waves of data collection. The interwave response rates were $82 \%, 87 \%$, and $87 \%$ for waves 2,3 , and 4 , respectively.

\section{DATA ANALYSIS}

To investigate the process of stability and change in smoking status over the four waves, a series of Markov chain models were fitted to these data. Markov chain models or autoregressive series are used to describe data where the expected value of the dependent variable at any time depends to some extent on the values of that variable at previous points in time. ${ }^{32}$ The models can be realised as loglinear models for tables cross-classifying smoker type at each wave. Zero-order models specify a main effects model - that is, testing if self-labelled smoking status is independent at each measurement point. First-order models specify the main effects and two-way interactions between the dependent variable measured at adjacent times-that is, self-labelled smoking status is related to smoking status measured at the previous wave. In addition to these effects, second-order models specify three-way interactions between variables measured at triples of adjacent time periods - that is, smoking status is related to smoking status measured at the previous two waves.

\section{ATTRITION BIAS}

Although the retention rates were high, there was some differential attrition according to respondent characteristics. Using characteristics from wave 1 data, the following differences were noted: $49 \%$ of young men vs $37 \%$ of young women dropped out. Older respondents were more likely to drop out than younger ones ( $64 \%$ of the oldest age group vs $34 \%$ of the youngest age group). "Heavy smokers" were also more likely to drop out $(61 \%)$ than "nonsmokers" $(37 \%)$. Differences using wave 2 characteristics were also investigated by comparing the 686 respondents who completed this wave but were not part of the 1903 with complete data. Relative to students, more unemployed people and full time workers dropped out of the study (33\% of unemployed and $37 \%$ of workers vs $22 \%$ of full time students). Those who lived with friends were more likely to drop out (33\%) than those in other accommodation arrangements. There was some differential attrition according to parental smoking status. Those whose fathers smoked were more likely to drop out $(30 \%)$ than those whose fathers did not $(25 \%)$, and dropouts were higher among those whose mothers smoked (30\%) compared with those whose mothers did not smoke (24\%). There were no differences in attrition with respect to language spoken at home or parental education.

\section{Results}

SEX DIFFERENCES

For all four waves of data, young men were approximately $10 \%$ more likely to report being "non-smokers" than young women. Population estimates from Hill, White, and Segan, ${ }^{4}$ 


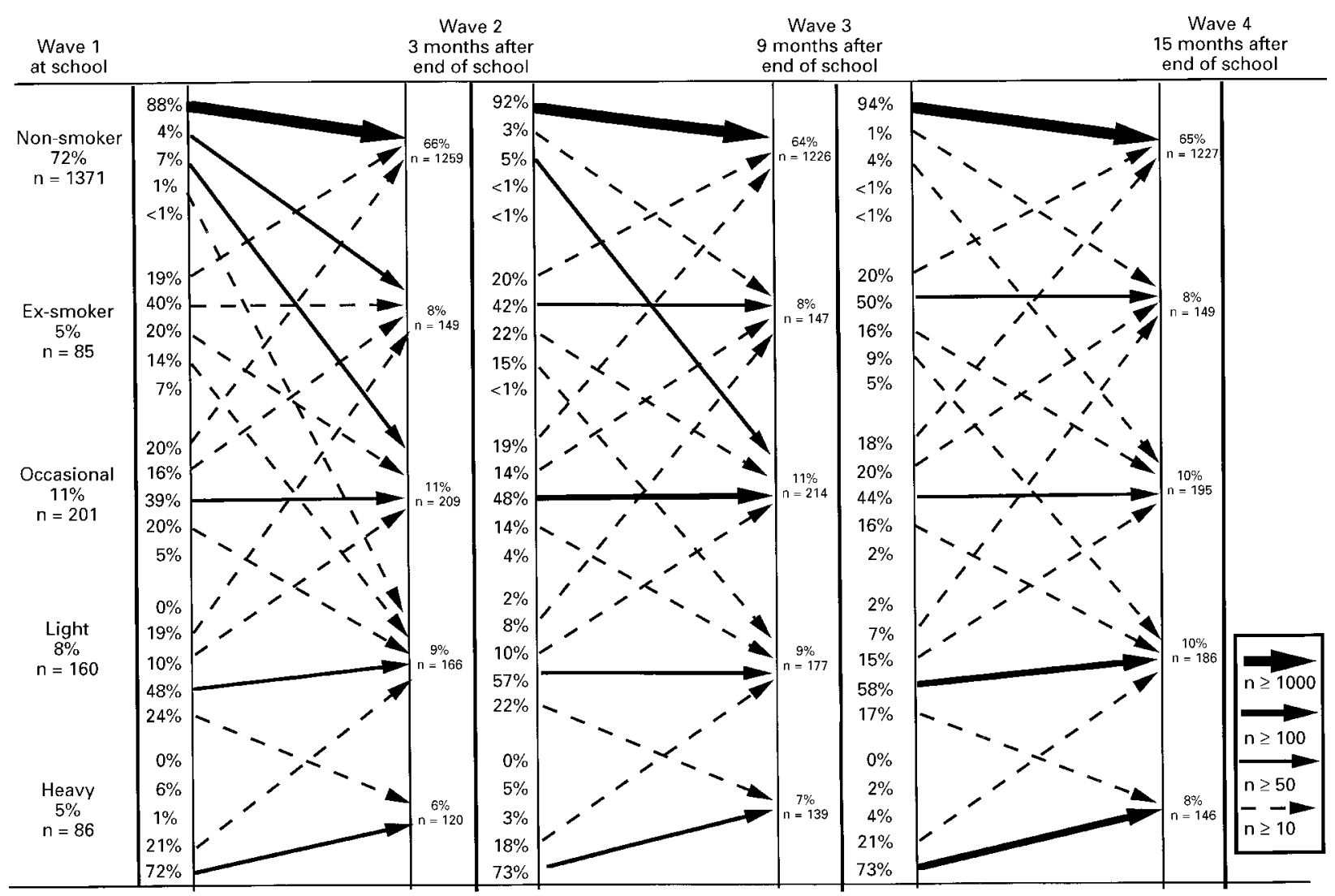

Figure 1 Changes in smoking status among school leavers over three six-month intervals.

Table 2 Consistency of self-labelled smoking status over the four waves

\begin{tabular}{lrrrrr}
\hline \multirow{2}{*}{$\begin{array}{l}\text { Wave 1 smoker-type } \\
\text { label }\end{array}$} & \multicolumn{2}{c}{$\begin{array}{l}\text { Used same label } \\
\text { waves 1-4 }\end{array}$} & & \multicolumn{3}{c}{$\begin{array}{l}\text { Changed label at } \\
\text { waves 2, 3, or 4 }\end{array}$} \\
\cline { 2 - 3 } \cline { 5 - 6 } \cline { 5 - 6 } & $\%$ & $n$ & & $n$ & $n$ \\
\hline Non-smoker & 57 & $(1075)$ & & 16 & $(296)$ \\
Ex-smoker & $<1$ & $(12)$ & & 4 & $(73)$ \\
Occasional & 1 & $(22)$ & & 9 & $(179)$ \\
Light smoker & 2 & $(33)$ & & 7 & $(127)$ \\
Heavy smoker & 2 & $(44)$ & & 2 & $(42)$ \\
Overall & 62 & $(1186)$ & & 38 & $(717)$ \\
\hline
\end{tabular}

suggest that slightly more 17 -year-old men are non-smokers at school. And Hill and White ${ }^{8}$ indicate that the difference in proportions of non-smokers between males and females in their early 20 s is about $7 \%$. The slightly greater size of the sex difference in the present study may be due to attrition biases. As the patterns of change over time (shown in figure 1) were virtually identical for both sexes, we only report aggregated data.

\section{TRACKING CHANGES IN SMOKING STATUS OVER} TIME

Most respondents (62\%) used the same smoker type label in each wave, with $57 \%$ of the total being "non-smokers" at all four waves (table 2). Thirty-eight per cent changed label on at least one of waves 2 to $4: 16 \%$ were nonsmokers at wave 1 . The other $22 \%$ who changed were predominantly occasional or light smokers at wave 1 .

Changes in smoker type reported at the four waves over three time intervals are displayed in figure 1 . The columns titled "At school", "3 months after", "9 months after", and "15 months after end of school" display the proportion of respondents in each smoker type category for the respective survey waves. The adjacent columns display the interwave changes in smoker type that occurred separately for each smoker type category. The five percentages show the distribution of smoker type responses for the subsequent wave for respondents from a given category on the previous wave.

A description of the non-smoker transitions from wave 1 to wave 2 may clarify interpretation of this figure. In wave 1 (at school), $72 \%$ of all respondents were "non-smokers". At the next survey period (wave 2), $88 \%$ of these respondents were also "non-smokers", 4\% were "ex-smokers", 7\% were "occasional smokers", and very small numbers were "light" or "heavy smokers". The $66 \%$ of all respondents who were "nonsmokers" at wave 2 are made up of the $88 \%$ from wave 1 who continued as non-smokers and small numbers who became "nonsmokers" from "ex-smoker" and "occasional". There were very few "light" and no "heavy" smokers who became "non-smokers" (as one would expect).

Focusing on the distribution of responses for each wave, the percentage of "non-smokers" changed the most, dropping from $72 \%$ at wave 1 to $65 \%$ at wave 4 . The number of people in the "occasional" and "light smoker" categories barely changed over the four waves of data. The "ex-smoker" and "heavy smoker" catego- 
Table 3 Parameter estimates for the reduced second-order Markov chain model

\begin{tabular}{lccccr}
\hline Matrix 1 Wave $A \rightarrow$ wave $B$ & \multicolumn{1}{l}{} & & \\
\hline & Wave $B$ & & & \\
\cline { 2 - 6 } & Non-smoker & Ex-smoker & $\begin{array}{l}\text { Occasional } \\
\text { smoker }\end{array}$ & $\begin{array}{l}\text { Light } \\
\text { smoker }\end{array}$ & $\begin{array}{l}\text { Heavy } \\
\text { smoker }\end{array}$ \\
Wave $A$ & $\mathbf{2 0 . 1 4}$ & $\mathbf{- 0 . 3 0}$ & $\mathbf{0 . 2 7}$ & $\mathbf{- 1 0 . 0 1}$ & $\mathbf{- 1 0 . 1 0}$ \\
\hline Non-smoker & 0.17 & $\mathbf{0 . 5 7}$ & 0.07 & -0.14 & $\mathbf{- 0 . 6 7}$ \\
Ex-smoker & 0.24 & -0.17 & $\mathbf{0 . 6 9}$ & -0.12 & $\mathbf{- 0 . 6 4}$ \\
Occasional smoker & $\mathbf{- 1 0 . 5 1}$ & 0.17 & -0.26 & $\mathbf{0 . 9 0}$ & $\mathbf{0 . 7 0}$ \\
Light smoker & $\mathbf{- 1 0 . 0 4}$ & -0.27 & $-\mathbf{0 . 7 7}$ & 0.37 & $\mathbf{1 0 . 7 1}$ \\
Heavy smoker & & & & &
\end{tabular}

Matrix 2 Wave $B \rightarrow$ wave $C$

\begin{tabular}{lcccrr}
\hline & \multicolumn{1}{l}{ Wave $C$} & & & \\
\cline { 2 - 6 } Wave B & Non-smoker & Ex-smoker & $\begin{array}{l}\text { Occasional } \\
\text { smoker }\end{array}$ & $\begin{array}{l}\text { Light } \\
\text { smoker }\end{array}$ & $\begin{array}{l}\text { Heavy } \\
\text { smoker }\end{array}$ \\
\hline Non-smoker & $\mathbf{2 0 . 4 7}$ & -0.18 & -0.01 & $\mathbf{- 1 0 . 3 0}$ & $\mathbf{- 0 . 9 8}$ \\
Ex-smoker & 0.17 & $\mathbf{0 . 9 5}$ & 0.03 & $\mathbf{- 0 . 3 1}$ & $\mathbf{- 0 . 8 4}$ \\
Occasional smoker & -0.11 & 0.11 & $\mathbf{0 . 7 2}$ & -0.05 & $\mathbf{- 0 . 6 7}$ \\
Light smoker & $\mathbf{- 1 0 . 2 2}$ & $\mathbf{- 0 . 3 7}$ & -0.15 & $\mathbf{1 0 . 1 2}$ & $\mathbf{0 . 6 2}$ \\
Heavy smoker & $\mathbf{- 1 0 . 3 1}$ & $\mathbf{- 0 . 5 1}$ & $\mathbf{- 0 . 5 9}$ & $\mathbf{0 . 5 4}$ & $\mathbf{1 0 . 8 7}$ \\
\hline
\end{tabular}

Matrix 3 Wave $A \rightarrow$ wave $C$

\begin{tabular}{lccrrr}
\hline \multicolumn{5}{l}{ Wave $C$} \\
\cline { 2 - 6 } Wave $A$ & Non-smoker & Ex-smoker & $\begin{array}{l}\text { Occasional } \\
\text { smoker }\end{array}$ & $\begin{array}{l}\text { Light } \\
\text { smoker }\end{array}$ & $\begin{array}{l}\text { Heavy } \\
\text { smoker }\end{array}$ \\
\hline Non-smoker & $\mathbf{1 0 . 2 8}$ & $\mathbf{- 0 . 3 4}$ & 0.14 & $\mathbf{- 0 . 3 5}$ & $\mathbf{- 0 . 7 3}$ \\
Ex-smoker & -0.11 & $\mathbf{0 . 6 9}$ & -0.03 & -0.21 & $\mathbf{- 0 . 3 4}$ \\
Occasional smoker & -0.17 & 0.05 & $\mathbf{0 . 3 6}$ & 0.02 & -0.26 \\
Light smoker & -0.31 & $\mathbf{- 0 . 4 1}$ & -0.15 & $\mathbf{0 . 5 7}$ & -0.30 \\
Heavy smoker & $\mathbf{- 0 . 6 9}$ & 0.01 & -0.32 & -0.03 & $\mathbf{1 0 . 6 3}$ \\
\hline
\end{tabular}

Bolded estimates: $|\mathrm{Z}|>1.96$.

Waves A, B, C correspond to waves 1, 2, 3 and waves $2,3,4$.

ries gained respondents over the later waves. About $90 \%$ of "non-smokers" said that they were "non-smokers" at each subsequent wave.

Across all three transitions, only $40-50 \%$ of ex-smokers called themselves "ex-smokers" at the next survey period. A sizeable proportion $(30-40 \%)$ reported having returned to smoking. Interestingly, about $20 \%$ of "ex-smokers" used the label "non-smoker" the next time. This suggests that they re-evaluated the meaning of the label "ex-smoker".

Fewer than half of the "occasional" smokers retained this label at each subsequent wave $(39 \%, 48 \%$, and $44 \%)$, and there were substantial changes in both directions, but more (33-38\%) moved to "non-smoker" or "ex-smoker" than to "light" or "heavy" $(18-25 \%)$.

About half or slightly fewer of the "light smokers" changed their smoking status category at the subsequent survey period; more progressed to "heavy" smoking than to lower categories. More than $70 \%$ of "heavy smokers" used the "heavy smoker" label at the next wave. Only small numbers reported being "exsmokers" in the wave after reporting being a "heavy smoker", suggesting that few quit in this group.

There were 152 respondents who were "light" or "heavy" smokers at all four waves. At wave 3, 63\% of these persistent smokers reported quitting for 24 hours or more in the last year: $11 \%$ made one quit attempt, $14 \%$ made two, $17 \%$ made three or four, and $21 \%$ made five or more. The proportion of this group who made quit attempts had dropped to
$49 \%$ in wave $4: 11 \%$ had made one, $15 \%$ two, $6 \%$ three or four, and $17 \%$ made five or more in the past year.

We calculated the analyses in figure 1 again, using the number of cigarettes smoked and number of days in the last week smoked to define the three current smoker categories. Essentially, the same pattern was found.

The Markov chain analyses revealed that the most parsimonious model that fitted the data was a reduced second-order model that specified main effects, two-way interactions for all adjacent time periods, and two-way interactions between waves 1 and 3 and waves 2 and 4. Further, it was assumed that parameter estimates for transitions within the two overlapping sequences were equal-that is, waves 1,2 , and 3 and waves 2,3 , and $4\left(\mathrm{G}^{2}\right.$ $(176)=169.57, \mathrm{p}=0.622)$. This suggests that the same behavioural sequence is repeated over waves 1 to 3 and waves 2 to 4 . The parameter estimates for this model are present in table 3 in which waves 1,2, 3 and waves 2, 3, 4 are represented as waves A, B, C. These estimates are the parameters of the fitted loglinear models, and the size of the estimate indicates the size of the effect. (Readers interested in the details of this analysis are welcome to contact the first author for more information.)

These analyses confirm the suggestions emerging out of an examination of figure 1 . They indicate that the most stable smoker-type categories are "non-smoker" and "heavy smoker", followed by "light smoker", with the least stable being "ex-smoker" and "occasional smoker". It also reveals a significant movement from "non-smoker" to "occasional smoker" at the wave A to wave B transition. From figure 1, it is apparent that this is most marked in the wave 1 to wave 2 transition. It is interesting to note that the movement from non-smoker to light smoker has a significant negative parameter, which suggests that non-smokers who are starting to smoke are likely to remain occasional smokers for six months or more before progressing to being light smokers. The double transition interactions - that is, from wave 1 to wave 3 and from wave 2 to wave 4 - show that remaining the same type for two successive waves increases the likelihood of remaining that type.

\section{CIGARETTE CONSUMPTION}

A small number of "ex-smokers" reported smoking in the past week $(14 \%, 8 \%, 8 \%$, and $6 \%$ for each wave, respectively). Overall, "ex-smokers" had a mean daily cigarette consumption of about a fifth of a cigarette. "Occasional smokers" averaged about one cigarette per day at each time period. "Light smokers" were smoking about four cigarettes a day when still a school student. This number almost doubled to about eight cigarettes 15 months after the end of school. "Heavy smokers" went from smoking an average of about 11 cigarettes a day to 17 a day over the same period. In contrast to the average daily consumption, the maximum daily consumption was relatively stable over the three time periods for each smoker type. Table 4 presents 
Table 4 Mean daily and maximum daily cigarette consumption for each smoking category

\begin{tabular}{|c|c|c|c|c|c|c|c|c|c|c|c|c|}
\hline & \multicolumn{3}{|c|}{$\begin{array}{l}\text { Wave } 1 \\
\text { At school }\end{array}$} & \multicolumn{3}{|c|}{$\begin{array}{l}\text { Wave } 2 \\
3 \text { Months after school }\end{array}$} & \multicolumn{3}{|c|}{$\begin{array}{l}\text { Wave } 3 \\
9 \text { Months after school }\end{array}$} & \multicolumn{3}{|c|}{$\begin{array}{l}\text { Wave } 4 \\
15 \text { Months after school }\end{array}$} \\
\hline & Mean & $(95 \%$ CIs) & $n$ & Mean & $(95 \% C I s)$ & $n$ & Mean & $(95 \% C I s)$ & $n$ & Mean & $(95 \% C I s)$ & $n$ \\
\hline \multicolumn{13}{|l|}{ Occasional smokers } \\
\hline Daily consumption & 0.74 & $(0.59-0.89)$ & 199 & 0.86 & $(0.68-1.04)$ & 208 & 0.85 & $(0.62-1.08)$ & 213 & 1.03 & $(0.71-1.35)$ & 182 \\
\hline Maximum consumption & - & & & 3.34 & $(2.65-4.03)$ & & 3.36 & $(2.72-4.00)$ & & 3.10 & $(2.45-3.75)$ & \\
\hline \multicolumn{13}{|l|}{ Light smokers } \\
\hline Daily consumption & 4.27 & $(3.79-4.75)$ & 160 & 5.97 & $(5.19-6.75)$ & 166 & 5.71 & $(5.01-6.41)$ & 177 & 7.71 & $(6.52-8.90)$ & 168 \\
\hline Maximum consumption & - & & & 11.43 & $(10.31-12.55)$ & & 11.55 & $(9.85-13.25)$ & & 11.97 & $(10.83-13.11)$ & \\
\hline \multicolumn{13}{|l|}{ Heavy smokers } \\
\hline Daily consumption & 10.81 & $(9.56-12.06)$ & 83 & 14.21 & $(12.85-15.57)$ & 116 & 15.29 & $(13.88-16.70)$ & 138 & 16.97 & $(15.56-18.38)$ & 142 \\
\hline Maximum consumption & - & & & 22.94 & $(20.99-24.89)$ & & 22.39 & $(20.66-24.12)$ & & 24.24 & $(22.40-26.08)$ & \\
\hline
\end{tabular}

$\mathrm{CI}=$ confidence interval.

the mean daily and maximum daily cigarette consumption among current smokers for "occasional", "light", and "heavy" smoker types across all four waves.

Overall, there was a net movement towards a higher level of smoking in terms of self-labelled smoker type and consumption. This trend was particularly evident over the first interval, which included leaving school. There was less transition back to lower levels of smoking.

\section{Discussion}

There was moderately high interwave stability in self-labelled smoker type, especially among "non-smokers" and "heavy smokers". Despite continuity in smoking (or non-smoking) patterns for most people, more than a third $(38 \%)$ relabelled their type of smoking at some point over the study period. Importantly, about $40 \%$ of these people were initially nonsmokers; however, we recognise that many of these non-smokers have tried cigarettes before. These findings call into question public health strategies that focus prevention programmes solely on schoolchildren. There is moderate uptake of regular smoking in the first year after leaving school, which corresponds with findings from earlier work. ${ }^{18} 19$

Furthermore, there is considerable movement between categories. While those who see themselves as "heavy" smokers are likely to remain "heavy" smokers, "light" and "occasional" smokers frequently move categories. Interestingly, there was a significant movement from "non-smoker" to "occasional" smoker, but few people moved from "non-smoker" to "light" smoker over a year. This transition would appear to take longer and perhaps incorporate times of nonsmoking, before a period of stable light smoking was reached. Excluding those who remained non-smokers over the four waves, most show changes in their smoking involvement.

Reported consumption rises across waves for the self-described "light" and "heavy" smokers, suggesting that these labels, to some extent, reflect smoking relativities within peer groups. This finding justifies the use of self-referent labels, especially as consumptionbased definitions did not produce any notable differences in the pattern of transitions.

Because the heavy smokers were more likely to drop out of the study, the estimated proportion of non-smokers is inflated, so the estimate of transition towards smoking will be slightly inflated. It is also possible that the loss of the heavy smokers has resulted in an underestimate of the stability of that group. Another possible bias is that the mode of survey administration in wave 1 was different from waves 2 , 3 , and 4 . Reporting smoking status in the context of a school classroom may slightly reduce the proportion of people who admitted to smoking, although the work by Stanton et al ${ }^{31}$ suggests otherwise. Any such effect would inflate the estimated level of uptake after leaving school.

Average cigarette consumption among "light" and "heavy smokers" increased over 15 months after leaving school. By the end of the study period, the average consumption for "heavy" smokers (approximately 17 cigarettes per day) was only slightly lower than the average consumption for all adult smokers in the same population. ${ }^{8}$ The change in average consumption associated with self-labelled smoker type suggests that young adults have changed their conceptions of what constitutes a "light" or "heavy smoker" over time, perhaps anchoring their self labels around their perceptions of usual consumption among their peers. It is possible that as their peers' consumption increases, their awareness of this leads to a revision of what "light" and "heavy" mean in terms of daily consumption.

The term "ex-smoker" also seems to carry different connotations for different individuals. The transition to "non-smoker" was common from "ex-smoker". It seems plausible that this transition occurs among those who smoked experimentally, and after they had stopped completely for some time they reflected that they had never really been a regular smoker. Consistent with this, a similar transition was found from "occasional" smoker to "nonsmoker".

Despite the tendency to progress to higher levels, the fact that few of these school leavers moved rapidly to "light" or "heavy" suggests that there is a window of opportunity to intervene. In this context, we acknowledge that the shifting consumption levels associated with the labels of light and heavy smokers have the effect of reducing the proportions moving across categories as some increase consumption while remaining within the same category. In the absence of an addiction threshold, consumption-based definitions will not necessarily result in a more accurate estimate 
of those moving to a pattern of continuing regular consumption.

That initiation to smoking is still occurring after leaving school implies that prevention programmes should be extended beyond school. Young adults display a distinct pattern of quit attempts compared with older adults; they attempt to quit more frequently but are also more likely to relapse. ${ }^{33}$ The initiation and greater instability of use provide a yet-to-be exploited opportunity to intervene with "occasional" and "light" smokers before they become heavily dependent. It is vital to develop programmes appropriately targeted to reverse progression of smoking behaviour and to achieve permanent abstinence among this group of young adults. Such programmes will necessarily be different from prevention programmes focusing on never smoking the first cigarette, and from cessation programmes designed to help motivated self-acknowledged addicts to break their dependencies.

This research was generously funded by NRMA Insurance, without whose support it would not have been possible. We would also like to thank the following people from the Anti-Cancer Council of Victoria: Barbara McKenzie, Bronwyn Nixon, and Anne Gibbs for their pivotal role in data collection and Sonia Nicolas and Josie Italia for providing exceptional secretarial support.

1 Hawkins JD, Catalano RF, Miller JY. Risk and protective factors for alcohol and other drug problems in adolescence and early adulthood: implications for substance abuse prevention. Psychol Bull 1992;112:64-105.

2 Gritz ER. Reaching toward and beyond the Year 2000 goals for cigarette smoking. Cancer 1994;74:1423-32.

3 Clarke V, White V, Hill D, et al. School structural and policy variables associated with student smoking. Tobacco Control 1994:3:339-46.

4 Hill D, White V, Segan C. Prevalence of cigarette smoking among Australian secondary school students in 1993. Aust 7 Public Health 1995;19:445-9.

5 Raveis VH, Kandel DB. Changes in drug behavior from the middle to the late twenties: initiation, persistence and cesmidion of use. Am ₹ Public Health 1987;77:607-11.

6 Chen K, Kandel DB. The natural history of drug use from adolescence to the mid-thirties in a general population adolescence to the mid-thirties in a gen
sample. Am f Public Health $1995 ; 85: 41-7$.

7 US Department of Health and Human Services. The health consequences of smoking: nicotine addiction. A report of the Surgeon General, 1988. Rockville, Maryland: Public Health Service, Centers for Disease Control, Office on Smoking and Health, 1988. (DHHS Publication No (CDC) 88-8406.)

8 Hill DJ, White V. Australian adult smoking prevalence in 1992. Aust F Public Health 1995;19:305-8.

9 Borland R. Population estimates of occasional smoking among self-described smokers and non-smokers in Victoria, Australia. Tobacco Control 1994;3:37-40.

10 Conrad KM, Flay BR, Hill D. Why children start smoking cig

11 Chassin L, Presson CC, Sherman SJ, et al. The natural history of cigarette smoking: predicting young-adult smoking tory of cigarette smoking: predicting young-adult smoking
outcomes from adolescent smoking patterns. Health Psychol 1990;9:701-16.
12 Chassin L, Presson CC, Sherman SJ, et al. Four pathways to young-adult smoking status: adolescent socialyoung-adult smoking status: adolescent community sample. Health Psychol 1991;10:409-18.

13 Chassin L, Presson CCL, Sherman SJ, et al. The natural history of cigarette smoking and young adult social roles. $\mathcal{F}$ Health Soc Behav 1992;33:328-47.

14 Newcomb MD, McCarthy WJ, Bentler PM. Cigarette smoking, academic lifestyle, and social impact efficacy: an hood. $\mathcal{F}$ Appl Soc Psychol 1989;19:251-81.

15 Newcomb MD, McGee L. Influence of sensation seeking on general deviance and specific problem behaviors from adolescence to young adulthood. F Personality Soc Psychol 1991;61:614-28.

16 Schulenberg J, Bachman JG, O'Malley PM, et al. High school educational success and subsequent substance use: a panel analysis following adolescents into young adulthood. F Health Soc Behav 1994;35:45-62.

17 Bachman JG, O'Malley PM, Johnston LD. Drug use among young adults: the impacts of role status and social environment. I Personality Soc Psychol 1984;4:629-45.

18 US Department of Health and Human Services. Preventing tobacco use among young people. A report of the Surgeon General, 1994. Atlanta, Georgia: Public Health Service, Centers for Disease Control and Prevention, Office on Smoking and Health, 1994. (US Government Printing Office No S/N 017-001-00491-0.)

19 Bachman JG, Wadsworth KN, O'Malley PM, et al. Smoking, drinking, and drug use in young adulthood. The impacts of new freedoms and new responsibilities. Mahwah, New Jersey: Lawrence Erlbaum, 1997.

20 Jarvis MJ. A profile of tobacco smoking. Addiction 1994;9:1371-6.

21 Rowe DC, Chassin L, Presson CC, et al. Parental smoking and the "epidemic" spread of cigarette smoking. F Appl Soc Psychol 1996;26:437-54.

22 Rowe DC, Chassin L, Presson CC, et al. An "epidemic" model of adolescent cigarette smoking. F Appl Soc Psychol 1992;22:261-85.

23 Pierce JP, Evans N, Farkas AJ, et al. Tobacco use in California. An evaluation of the Tobacco Control Program 1989-1993. La Jolla, California: University of California, San Diego, 1994.

24 Shiffman S. Tobacco "chippers"-individual difference in tobacco dependence. Psychopharmacology 1989;97:53947

25 Guy SM, Smith GM, Bentler PM. Consequences of adolescent drug use and personality factors on adult drug use. $\mathcal{F}$ Drug Educ 1994;24:109-32.

26 Livson N, Leino EV. Adolescent personality antecedents of adult cigarette smoking: a longitudinal study. $\mathcal{F}$ Genet Psychol 1984;146:343-55.

27 Winefield HR, Winefield AH, Tiggermann M. Psychological attributes of young adult smokers. Psychol Rep 1992;70:675-81.

28 Johnston LD, O'Malley PM, Bachman JG. National survey results on drug use from the Monitoring The Future Study, 1975-1994 Vol. II. Rockville, Maryland: US Department of Health and Human Services, National Institute on Drug Abuse, 1996.

29 Australian Bureau of Statistics. Schools Australia 1994. ABS publication catalogue 4221.0. Canberra, ACT: Australian Bureau of Statistics.

30 Hill DJ, Wilcox S, Gardner G, et al. Tobacco and alcohol use among Australian secondary schoolchildren. Med $\mathcal{F}$ Aust among Australian

31 Stanton WR, McClelland M, Elwood C, et al. Prevalence, reliability and bias of adolescents' reports of smoking and quitting. Addiction 1996;91:1705-14.

32 Bishop Y, Fienberg S, Holland PW. Discrete multiseriate analysis: theory and practice. Cambridge, Massachusetts: MIT Press, 1975.

33 Pallonen UE, Murray DM, Schmid L, et al. Patterns of selfinitiated smoking cessation among young adults. Health Psychol 1990;9:418-26. 